\title{
Sierpinski Carpet Fractal Antenna for Multiband Applications
}

\author{
R. Mohanamurali \\ Final year M.Tech. (Electronics) \\ Department of Electronics Engineering \\ Pondicherry University
}

\author{
T. Shanmuganantham \\ Assistant Professor \\ Department of Electronics Engineering \\ Pondicherry University
}

\begin{abstract}
A Planar antenna with Microstrip feed Sierpinski carpet fractal geometry for multiband applications is presented. The multiband behavior is analyzed through two fractal iterations. Self similarity property of fractal technology is applied in the antenna design to reduce the physical size, increase bandwidth and gain. The proposed antenna covers multi bands such as 1.8/5.59/5.78/6.4/6.63/7.84 GHz. The parameters of the antenna such as radiation pattern, return loss and Gain are simulated using the method of moments (IE3D) software.
\end{abstract}

\section{General Terms}

Fractal, radiation pattern, gain

\section{Keywords}

Multiband, Self-similarity, Space filling

\section{INTRODUCTION}

Fractal is a new class of geometry that was proposed by 'Mandelbrote' [1]. Fractal concepts are employed in the field of antenna engineering to develop new types of antennas with prolific characteristics. Fractal shaped antennas exhibits some interesting features due to their geometrical properties [2]. Surface mounted antennas in cars, trains, aircrafts, satellite etc., needs to be smaller in size, light weight so that it consumes less fuel. Here space filling property of fractal antenna plays a vital role in the miniaturization [3] of antennas. This property is exploited through higher order [4] fractal concept.

Self similarity and space filling properties of fractal antennas is utilized in the design of antennas with notable characteristics like multiband behavior and miniaturization. Self similarity means that an object is build of sub units and subunits on multiple levels which tries to figure out the structure of entire object [5].

Sierpinski carpet antenna[6] based on fractal geometry are low profile antennas, moderate gain and can be operated at multiband of frequencies leads to a multi functional structure. This type of wideband [7] antenna displays high self similarity and symmetry [8].

\section{ANTENNA DESIGN}

The basic structure of Sierpinski antenna is built from a regular Microstrip patch and runs through several iterations to generate multiband characteristics[9][10].

The width of the microstrip patch antenna is given by [11],

$$
\begin{aligned}
& \text { Width }(W)=\frac{c}{2 f_{0}} \sqrt{\frac{2}{\left(\varepsilon_{r}+1\right)}} \\
& \varepsilon_{\text {reff }}=\frac{\left(\varepsilon_{r}+1\right)}{2}+\frac{\left(\varepsilon_{r}-1\right)}{2}\left(1+12 \frac{h}{W}\right)^{-1 / 2} \\
& L_{e f f}=\frac{c}{2 f_{0} \sqrt{\varepsilon_{\text {reff }}}}
\end{aligned}
$$

$$
\Delta L=0.412 h \frac{(\varepsilon \text { reff }+0.3)\left(\frac{W}{h}+0.264\right)}{(\varepsilon \text { reff }-0.258)\left(\frac{W}{h}+0.8\right)}
$$

$$
\operatorname{Length}(L)=L_{e f f}-2 \Delta L
$$

Where

$c \quad=$ Velocity of light in free space.

$f_{0} \quad=$ Operating resonant frequency.

$\varepsilon_{r} \quad=$ Dielectric constant of the substrate used.

$\varepsilon_{\text {reff }}=$ Effective dielectric constant .

$h \quad=$ Height of the substrate.

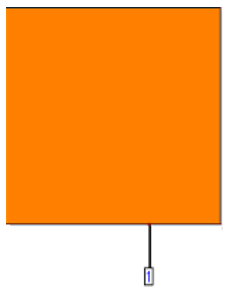

(a)

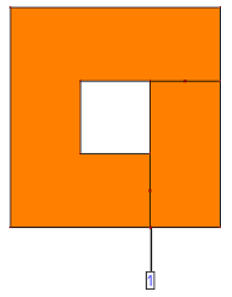

(b)

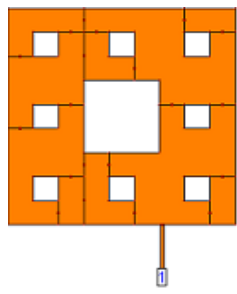

(c)
Figure 1: Antenna Layout (a) Zero iteration (b) First iteration (c) Second iteration 
The Substrate chosen for implementing this antenna is FR4 of thikness $1.59 \mathrm{~mm}$ and $\tan \delta=0.012$. The length of the square patch is found to be $37 \mathrm{~mm}$.

Let $\mathrm{Nn}$ be the number of black boxes, $\mathrm{Ln}$ is the scale factor for length of a side of white boxes, An is the scale factor for fractional area of black boxes after the nth iteration[12].

$$
\begin{aligned}
& N_{n}=8^{n} \\
& L_{n}=(1 / 3)^{n} \\
& A_{n}=L_{n}^{2} N_{n}=(8 / 9)^{n}
\end{aligned}
$$

First iteration of Microstrip carpet structure is designed by dividing a square into nine smaller squares. Then the square at the center is eliminated which results in 8 squares.

$$
L_{n}=(1 / 3)^{1}=0.33
$$

$\mathrm{L}_{1}$ is the scale factor for first iteration. The length of the small square is determined by taking the product of $\mathrm{L}_{1}$ and actual size of a square i.e $36.875 \mathrm{~mm}$. Length of small square is 12.3 . The $A_{1}$ is the scaling factor for the fractional area after performing first iteration. For basic square patch antenna, the area $\left(\mathrm{A}_{0}\right)$ is $37 \times 37 \mathrm{~mm}^{2}$. The area of the small square at the center is $12.3 \times 12.3=151.29 \mathrm{~mm}^{2}$. This smaller square is removed and hence the effective area becomes

$$
\begin{aligned}
& \text { Area }_{1}=1369-151.29=1217.77 \mathrm{~mm}^{2} . \\
& A_{1}=\frac{\text { Area }_{1}}{A_{0}}=0.889
\end{aligned}
$$

Hence the antenna area is reduced by $11.1 \%$.

Similarly after second iteration size is further reduced by $20.8 \%$.[13]

\section{RESULTS AND DISCUSSION}

Initially the square was designed and simulated. Then Sierpinski carpet fractal geometry is used and two iterations were performed and simulated using IE3D software [14]. For optimization, simulation have been repeated at various feed positions.

\subsection{Zero Iteration}

The figures 2, 3 and 4 show the simulation results of zero iteration. The square patch resonates at the frequency of $1.8 \mathrm{GHz}$ with a return loss of $-33 \mathrm{~dB}$.

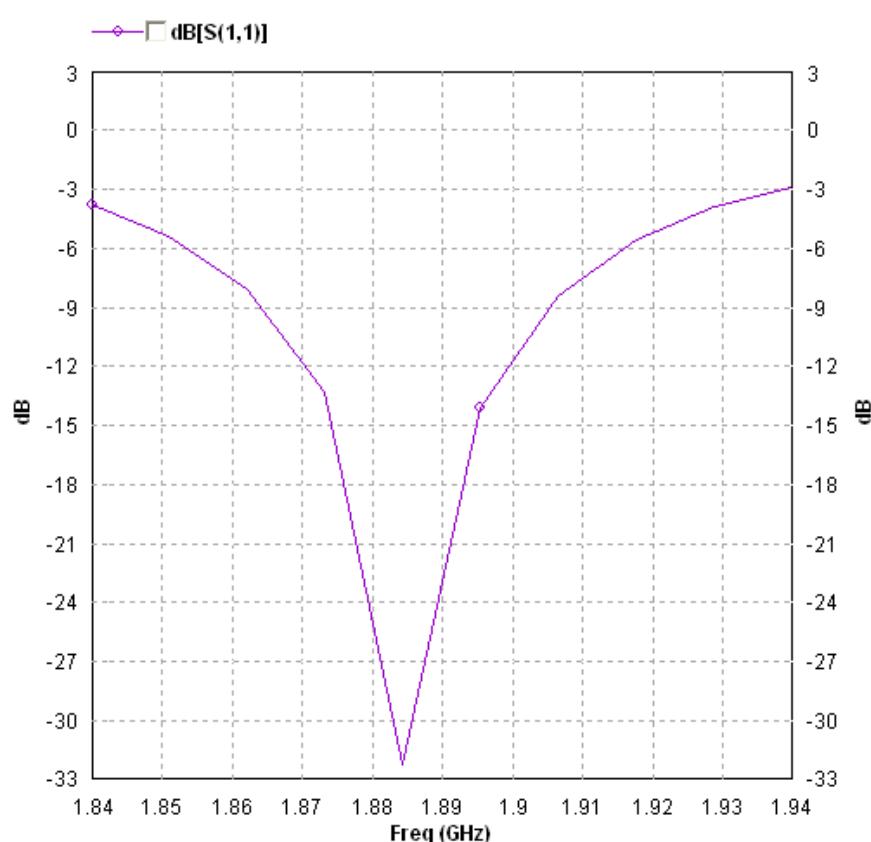

Fig 2 : Return Loss for iteration 0

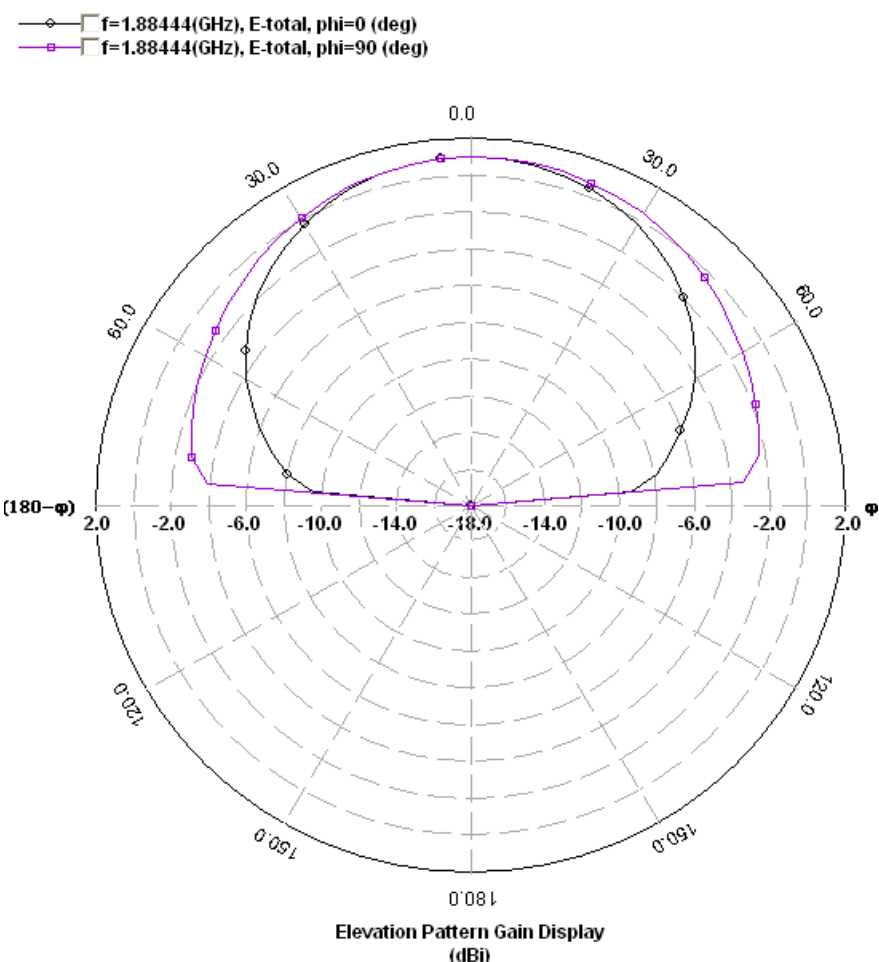

Fig 3 : Elevation Pattern for iteration 0 


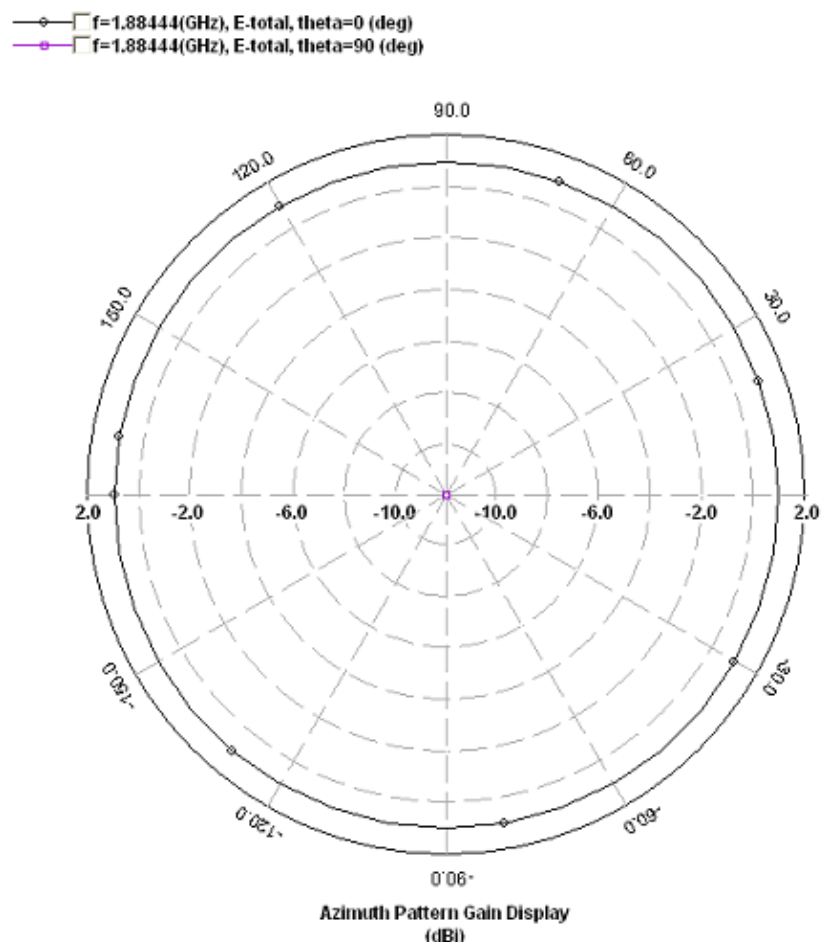

Fig 4 : Azimuth Pattern for iteration 0

\subsection{First Iteration}

The first iteration of the fractal antenna is performed and its simulated results are shown in figure 5, 6 and 7. After first iteration the Sierpinski carpet antenna resonates at two different frequencies namely $5.78 \mathrm{GHz}$ and $6.63 \mathrm{GHz}$ with the better return loss of $-14.09 \mathrm{~dB}$ and $-22.63 \mathrm{~dB}$ respectively.

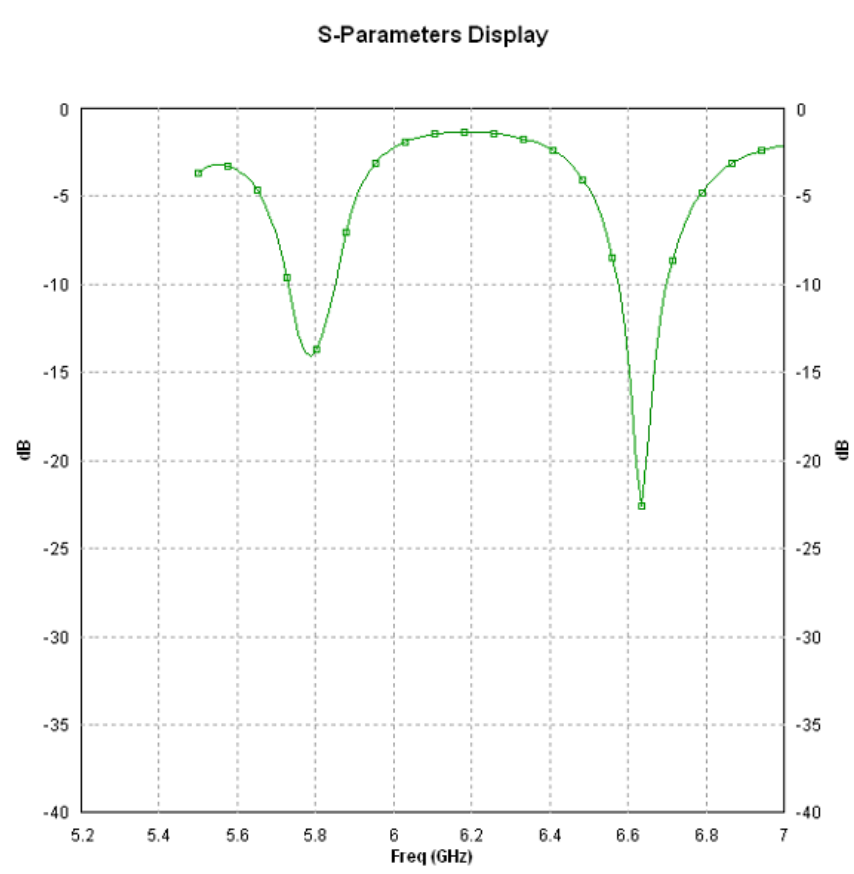

Fig 5 : Return Loss for iteration 1

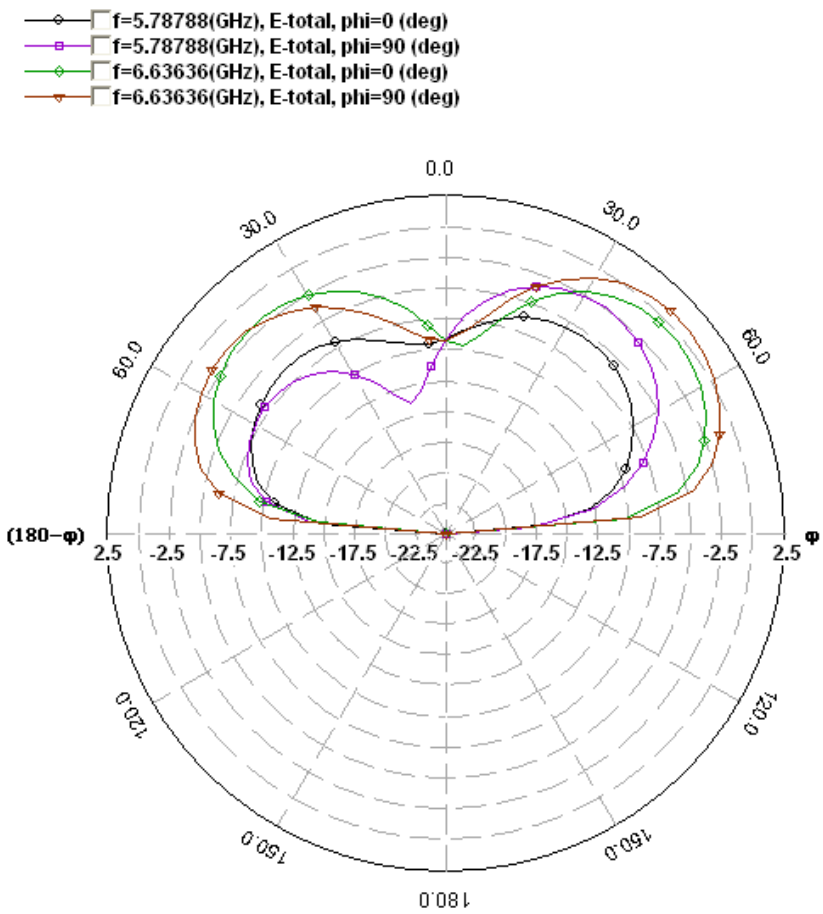

Elevation Pattern Gain Display

Fig 6 : Elevation Pattern for iteration 1
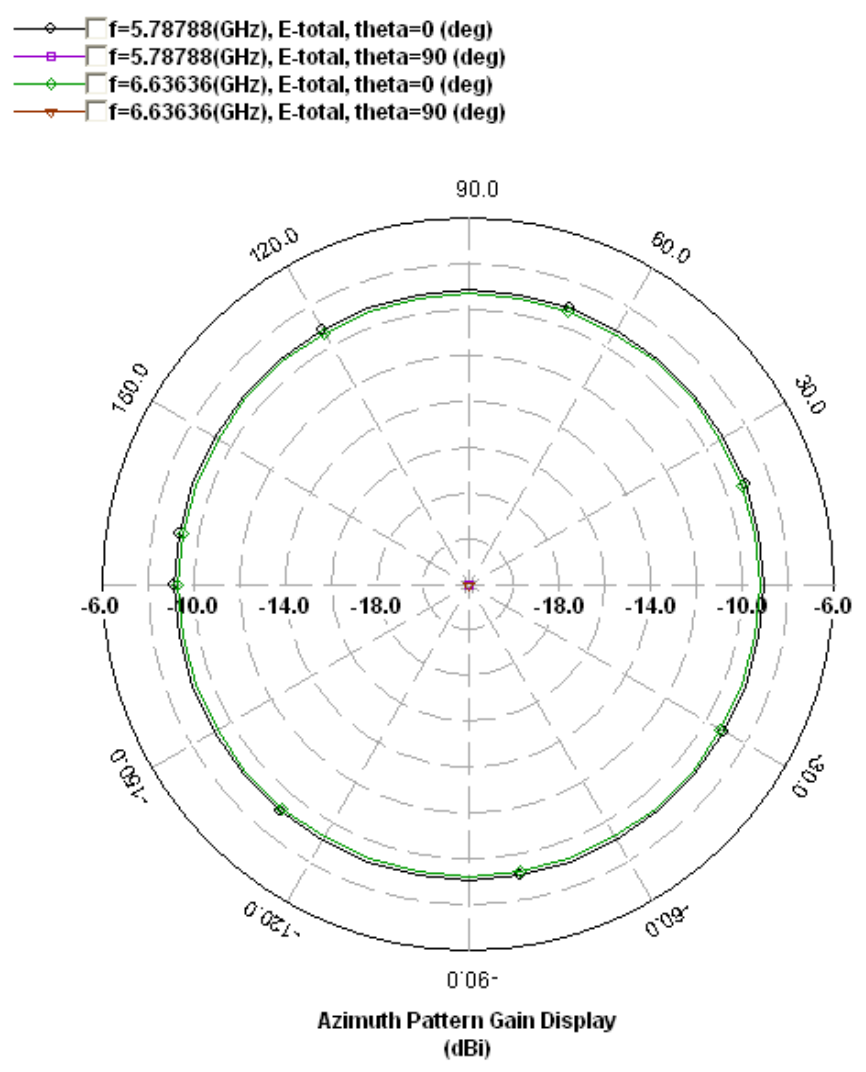

Fig 7 : Azimuth Pattern for iteration 1 


\subsection{Second Iteration}

Sierpinski carpet antenna has gone through the second iteration to exhibit the multiband characteristics at $5.59 \mathrm{GHz}$, $6.4 \mathrm{GHz}$ and $7.84 \mathrm{GHz}$ with the return loss of $-16.86 \mathrm{~dB}$, $-15.15 \mathrm{~dB}$ and $-18.87 \mathrm{~dB}$ respectively. The simulation results are shown in figure $8,9 \& 10$.

\section{S-Parameters Display}

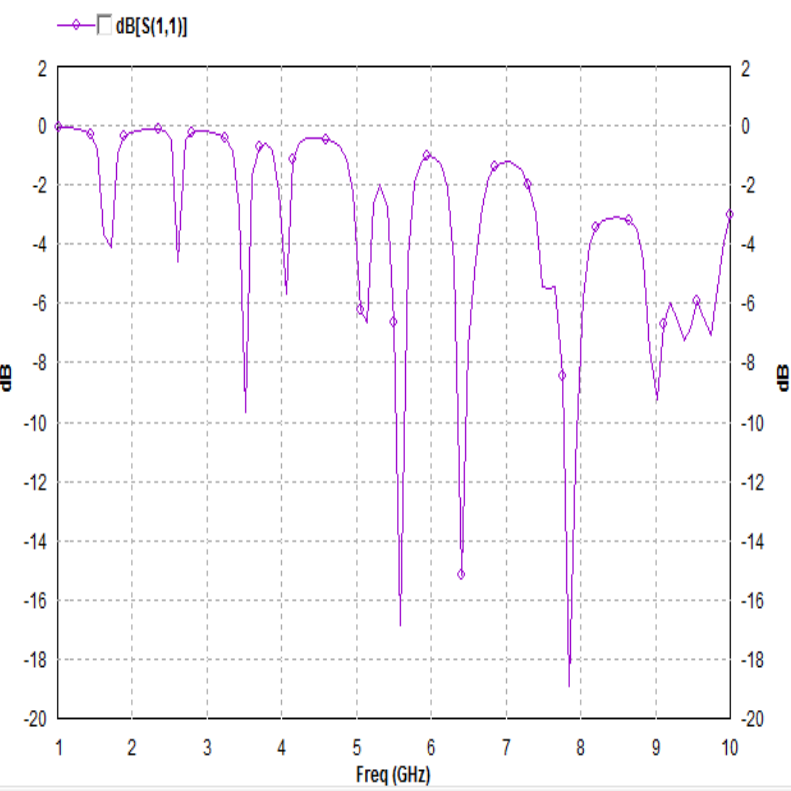

Fig 8 : Return Loss for iteration 2
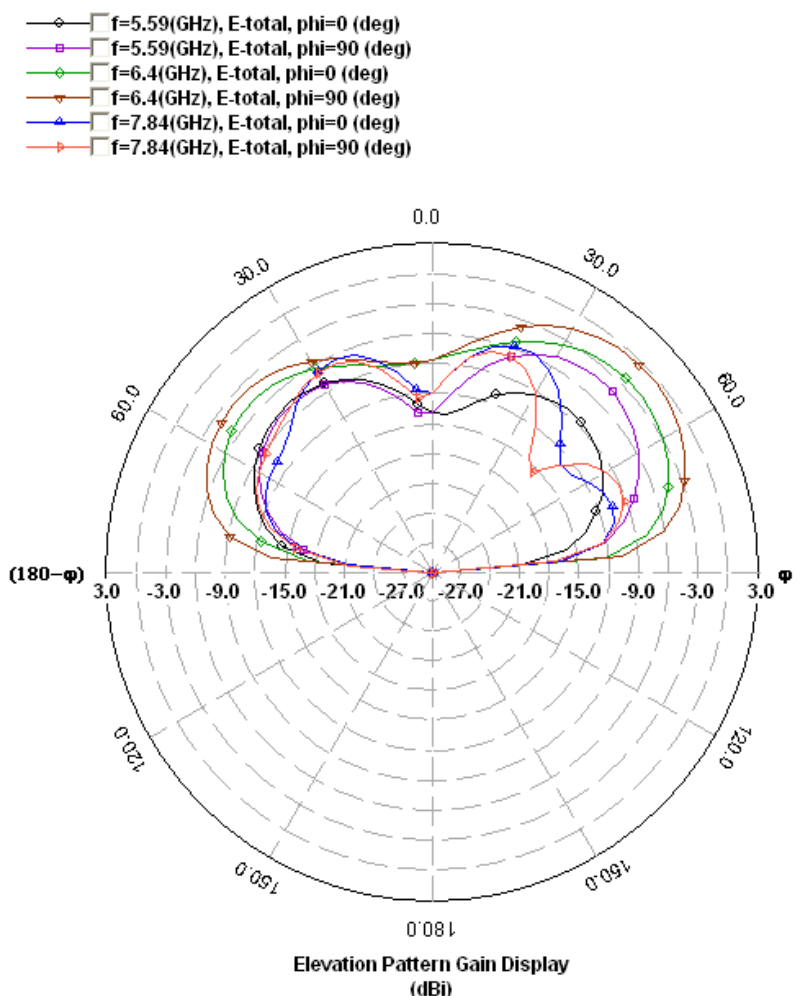

Fig 9 : Elevation Pattern for iteration 2
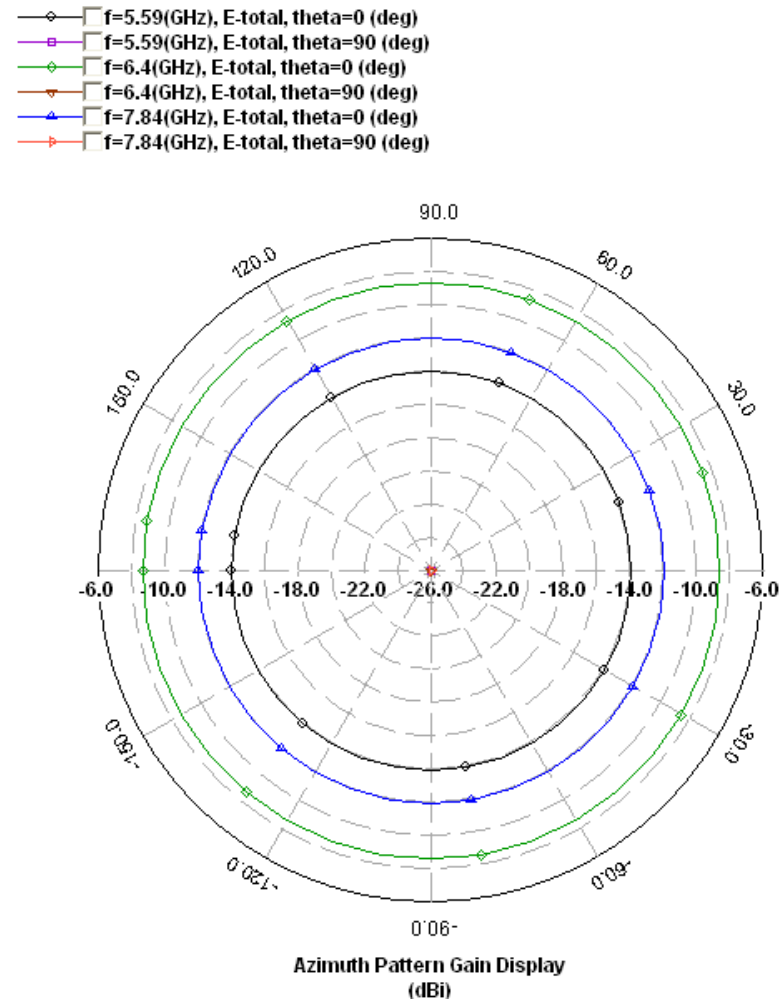

Fig 10 : Azimuth Pattern for iteration 2

\section{CONCLUSION}

The Microstrip Sierpinski carpet fractal shape antenna is designed for multiband operation has been presented. The simulated result shows that the antenna is suitable for 1.8/5.59/5.78/6.4/6.63/7.84 GHz wideband applications. Microstrip Sierpinski carpet antenna is designed and iterated up to second iteration to exhibit multiband behavior. To overcome the problem in the positioning of antenna feed for higher iterations, Aperture coupling can be employed.

\section{ACKNOWLEDGMENTS}

We would like to thank everyone who has been involved in this project directly or indirectly for their help and contribution.

\section{REFERENCES}

[1] B. B. Mandelbrot. 1983. The Fractal Geometry of Nature. San Francisco. 152-180.

[2] Werner, D. H. and S. Ganguly, "An overview of fractal antenna engineering research", IEEE Antennas and Propagation Magazine, Vol.45, 2003.

[3] J. P. Gianvittorio and Y. Rahmat-Samii. 2002. Fractal antennas: A novel antenna miniaturization technique, and applications. IEEE Antennas and Propagation. Mag. vol. 44(Feb. 2002). 20-36.

[4] J. L. Vehel, E. Lutton, and C. Tricot. 1997. Fractals in Enginnering. Springe-Verlag London. 222-236.

[5] W.L. Chen and G.M. Wang. 2008. Small size edge-fed Sierpinski carpet microstrip patch antenna. PIERS C, Vol.3.

[6] Constantine A. Balanis. 1997. Antenna Theory Analysis and Design. John Wiley and Sons Inc. 
[7] M. Naghshvarian-Jahromi. Novel wideband planar fractal monopole antenna. IEEE Trans. Antennas Propagation magazine. vol. 56 (Dec. 2008). 12.

[8] Werner, D. H. and S. Ganguly. 2003. An overview of fractal antenna engineering research. IEEE Antennas and Propagation magazine.Vol.45(Feb.2003).38

[9] J. Hwang, S. Jung, S. Kang and Y. Kim. 2011. Compact Wound-Type Slot Antenna With Wide Bandwidth. IEEE Antennas and Wireless Propagation Letters.Vol. 10.

[10] James, J. R. and P. S. Hall. 1989. Handbook of Microstrip Antennas. Peter Peregrinus.UK.

[11] Ramesh Garg, Prakash Bhartia, Inder Bahl,Apisak Ittipon. 2000. Microstrip Antenna Design Handbook. Artech House.

[12] Abd M.F, Ja'afar A.S \& Abd Aziz M.Z.A. 2007. Sierpinski Carpet Fractal Antenna. Proceedings of the 2007 Asia-Pacific conference on applied Electromagnetics. Melaka.

[13] M.K. A. Rahim, N. Abdullah, and M.Z. A. Abdul Aziz. 2005. Micro Strip Sierpinski Carpet Antenna Design. IEEE Transaction on Antenna and Propagation.

[14] Mentor Graphics www.mentorgraphics.com.

\section{AUTHORS BIOGRAPHY}

R. Mohanamurali was born on $4^{\text {th }}$ October, 1977. He received his Bachelor degree in Electronics and Communication Engineering from Anna University, Chennai. He has around eight years of teaching experience in Dr.Pauls
Engineering College and IFET College of Engineering in Tamilnadu. He has one year industrial experience in High power transmitters, All India Radio, Chennai. He has published paper in one International and national conference. $\mathrm{He}$ is pursuing M.Tech degree in Electronics, Department of Electronics Engineering, Pondicherry University. His research area includes Antennas, Fractal structures, Electromagnetics etc. He is the life member of ISTE.

T.Shanmuganantham was born May 12, 1974. He received B.E. degree in Electronics and Communication Engineering from University of Madras in 1996, M.E. degree in Communication Systems from Madurai Kamaraj University in 2000 and Ph.D. degree (Gold Medal) in the area of Antennas from National Institute of Technology, Tiruchirappalli, India under the guidance of Dr.S.Raghavan, Professor of ECE. He has 15 years of teaching experience in various reputed Engineering colleges such as SSN College of Engineering, Chennai, National Institute of Technology and Science, Chennai, PKIET, Karaikal. He has been with the Department of Electronics Engineering, School of Engineering \& Technology, Pondicherry University, Pondicherry as an Assistant Professor since 2010. His research interest includes Antennas, Microwave \& Millimeter-wave Engineering, Microwave Integrated Circuits, MEMS/NEMS, Metamaterials, Computational Electromagnetics, EMI/EMC, RF MEMS, RFIC Design, Optical Communication, Soft Computing for RF \& Microwave Engineering, Terahertz Technology. He has published 40 research papers in various national and International level Journals and Conferences. He is a member in IEEE, Life Member in IETE, Institution of Engineers, CSI, Society of EMC, ISTE, ISSS, OSI, ISI and ILA. 